\title{
Kawasaki disease: two case reports from the Aga Khan Hospital, Dar es Salaam- Tanzania
}

\author{
Mariam Noorani ${ }^{*}$ (D) and Nuruddin Lakhani
}

\begin{abstract}
Background: Kawasaki disease is a common childhood vasculitis which may result in cardiovascular morbidity if not adequately treated. Its epidemiology in the African region is not well described. Its features may mimic other childhood infections and hemoglobinopathies and it is rarely diagnosed in the East African region. These are the first reports of this disease from Tanzania.

Case presentation: We present two cases of complete Kawasaki disease seen over a 2 year period and diagnosed as per the criteria defined by the American Heart Association. One child was and infant and the other a 3 year old. Both of them presented with a prolonged fever and mucocutaneous findings. None of the children developed coronary artery aneurysms. One was treated with aspirin alone and the other with both aspirin and intravenous immunoglobulin. Both children had complete recovery and did not have any cardiovascular sequelae.

Conclusion: Kawasaki disease may be more common in the East African region than previously thought. It should be considered as a differential diagnosis in children who present with a prolonged fever of greater than 5 days and mucocutaneous findings. More awareness about this condition, its epidemiology, diagnosis and management are required in order to prevent the cardiovascular morbidity associated with it.
\end{abstract}

Keywords: Kawasaki, Vasculitis, Coronary aneurysms, Tanzania, Intravenous immunoglobulin, Rash, Fever

\section{Background}

Kawasaki disease is one of the most common vasculitides in childhood. It occurs predominantly in infants and young children and has long term cardiovascular morbidity due to coronary artery lesions if not adequately treated [1]. It is the leading cause of acquired heart disease in children in developed countries. The highest incidence is in Asia with almost 1 in a 100 children in Japan having the disease by age 5 [2]. In Africa, two cases were reported in South Africa in Caucasian children in 1980 but the first case in an African child was reported in Ivory Coast in 1981. Despite of sporadic cases being reported across many countries in Africa, mainly North Africa and the West African region, the epidemiological data for $\mathrm{KD}$ is limited for African countries [3-5].

The etiology of the disease remains unknown and several hypothesis exist in trying to explain the cause.

\footnotetext{
* Correspondence: mariam.noorani@akhst.org

Aga Khan Hospital, Dar es Salaam, Tanzania
}

Epidemiologic data suggest that an infectious agent may be causing the disease in genetically susceptible individuals [6]. The classic presentation of the disease occurs in children below 5 years. This suggests that there is an environmental trigger to which children mount an immune response after which the disease no longer manifests [7]. Postulated infectious agents include variants of normal flora which are induced by environmental factors such as improved hygiene [8]. Pathogenetic mechanisms postulated to result in endothelial injury include that of a protein homeostasis system in which immune cells target pathogenic proteins bound to endothelial cells resulting in host cell injury [9].

The initial symptoms are of a febrile illness lasting longer than 5 days with other mucocutaneous features including a rash, conjuctivitis and adenopathy. Diagnostic criteria exist to make a diagnosis of both complete and incomplete forms of disease [10]. If left untreated, the symptoms resolve in about 10 days. However, the coronary artery lesions may lead to long term cardiovascular complications

(c) The Author(s). 2018 Open Access This article is distributed under the terms of the Creative Commons Attribution 4.0 International License (http://creativecommons.org/licenses/by/4.0/), which permits unrestricted use, distribution, and reproduction in any medium, provided you give appropriate credit to the original author(s) and the source, provide a link to the Creative Commons license, and indicate if changes were made. The Creative Commons Public Domain Dedication waiver (http://creativecommons.org/publicdomain/zero/1.0/) applies to the data made available in this article, unless otherwise stated. 
including myocardial infarction, heart failure and arrhythmias. Treatment in the acute phase reduces the incidence of coronary artery lesions from 25 to $30 \%$ to $3-5 \%$ [11]. Currently, the recommended treatment is intravenous immunoglobulin in addition to acetylsalicylic acid at high doses [10].

In sub-saharan Africa, children suffer from many tropical and infectious diseases that present with symptoms similar to those of kawasaki disease such as fever, irritability and a rash. Common conditions include malaria, typhoid fever, meningitis and viral exanthems such as measles and roseola infantum. Other conditions that may mimic this disease include sickle cell dactylitis and infection with group A beta hemolytic streptococcus. A high index of suspicion is hence required to identify cases of kawasaki disease and institute early treatment.

We report here 2 cases of kawasaki disease seen at our institution that met diagnostic criteria defined by the American Heart Association. These are the first reports in published literature from the East African region.

\section{Case presentations \\ Case 1}

A.M was a 3 year old female child of African ethnicity who presented in July 2012 with a 8 day history of high grade fever and a 1 day history of swelling of the hands and feet. (Table 1 - timeline of case 1). She had received oral antibiotics, anti malarials and antihistamines with no improvement in symptoms. Her past medical history had been uneventful and her vaccinations were uptodate.

On examination, she was alert, had dry, red lips and non pitting edema on her hands and feet. She had cervical nodes measuring about $0.5 \mathrm{~cm}$. Her cardiovascular exam was normal. She was admitted for further work up for the cause of her fever.

Her results showed an elevated WBC count of 36,000/ $\mu \mathrm{l}, \mathrm{Hb}$ of $9.1 \mathrm{~g} / \mathrm{dl}$ and platelets of $380,000 / \mu \mathrm{l}$. Her CRP was $173 \mathrm{mg} / \mathrm{l}$. Malaria antigen and slide were both negative. Her urinalysis was normal. She was started empirically on ceftriaxone for presumed bacteremia and blood and urine cultures were sent. A differential diagnosis of sickle cell anaemia with dactylitis was also made and a peripheral smear, reticulocyte count and sickling test were requested. The reticulocyte count was low with a percentage of 0.38 . Sickling test was negative and the peripheral smear was normal.

She continued to have fever spikes despite the antibiotics and then developed a maculopapular hyperemic rash on her chest. A diagnosis of incomplete kawasaki disease was now made which met 3 out of the 5 required criteria. An echocardiogram was done which showed normal coronary arteries. High dose aspirin was started at $80 \mathrm{mg} / \mathrm{kg} /$ day. IVIG was not available at the institution at that time. A repeat complete blood count showed some improvement in white blood cells $(28000 / \mu \mathrm{l})$ but elevated platelets of $644000 / \mu \mathrm{l}$. The blood and urine culture were both reported as negative after $48 \mathrm{~h}$.

The child was then flown out to Nairobi, Kenya for IVIG treatment which she received uneventfully. She was discharged on low dose aspirin and subsequent echocardiograms remained normal.

\section{Case 2}

W.I was an 8 month old infant of African ethnicity who presented in August 2013 with a 6 day history of a high grade fever with temperatures upto 39 degrees celsius. (Table 2 - Timeline of case 2). This was associated with redness of the eyes, lips and mouth. He had been treated at various health facilities with antimalarials and 2 antibiotics: cefalexin and coamoxiclav. He had also received paracetamol, ibuprofen and diclofenac injections to control the fever. His past medical history was uneventful and his vaccines were uptodate. He had attained milestones appropriately.

On examination, the child was irritable and difficult to console. He was febrile with a temperature of $38.5{ }^{\circ} \mathrm{C}$ and was not pale. He had dry, cracked, hyperemic lips and conjuctival injection bilaterally. Cervical nodes were not palpable. He had a papular rash on the neck and at the site of the BCG scar. The rest of his physical exam was normal.

A presumptive diagnosis of incomplete kawasaki disease was made meeting 3 of the five criteria required in addition to the fever. A complete blood count showed mild anaemia with normal platelet count. (WBC: 9.07

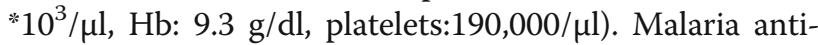
gen and blood slide were both negative. He was started on high dose aspirin at $90 \mathrm{mg} / \mathrm{kg} /$ day as IV IG was not available in our institution at that time. An echocardiogram was done which showed normal coronary arteries and normal cardiac function.

His fever resolved after $72 \mathrm{~h}$ and he developed swelling of the hands and feet which now confirmed the diagnosis of complete kawasaki disease. The aspirin dose was reduced to $5 \mathrm{mg} / \mathrm{kg} /$ day after the fever subsided. The platelet count was repeated and it showed elevated platelets of $742,000 / \mu l$. The CRP was also high: $153 \mathrm{mg} / \mathrm{l}$.

On follow up after a week, the limb swelling had reduced and he had skin exfoliation. His CRP had reduced to $60 \mathrm{mg} / \mathrm{l}$ and the platelets were $605,000 / \mu \mathrm{l}$.

A follow up echo done after 1 month was normal and the aspirin was stopped after the hematological parameters had normalised. He has subsequently remained well with no cardiovascular sequelae.

\section{Discussion and conclusions}

Both cases described above presented to us after a prolonged duration of fever and failure to respond to 
Table 1 Timeline of Case 1

\begin{tabular}{|c|c|c|c|}
\hline \multirow[t]{2}{*}{ Dates } & \multicolumn{3}{|l|}{ Relevant past medical history and interventions } \\
\hline & \multicolumn{3}{|c|}{ Previously well child with no chronic disease, growth and development appropriate for age, vaccinations complete as per schedule } \\
\hline Date & Summary from initial and follow up visits & Diagnostic testing & Interventions \\
\hline $\begin{array}{l}\text { July } 2012- \\
\text { Day } 1\end{array}$ & $\begin{array}{l}8 \text { days of fever } \\
1 \text { day of swollen hands and feet } \\
\text { Received antibiotics, antimalarials, antihistamines } \\
\text { On examination: dry lips, non-pitting edema, } \\
\text { cervical nodes } \\
\text { Diagnosis - probable sickle cell anaemia }\end{array}$ & 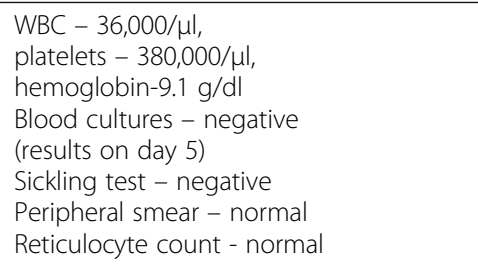 & IV ceftriaxone \\
\hline Day 3 & $\begin{array}{l}\text { Persistent fever. } \\
\text { Maculopapular rash on chest. } \\
\text { Diagnosis - probable } \\
\text { Kawasaki meeting } 3 \text { of } 5 \text { criteria }\end{array}$ & $\begin{array}{l}\text { Echocardiogram - normal coronary } \\
\text { arteries } \\
\text { Repeat blood count: elevated platelets - } \\
644,000 / \mu l\end{array}$ & High dose aspirin $-80 \mathrm{mg} / \mathrm{kg} /$ day \\
\hline Day 5 & Persistent fever & & Flew to Nairobi for IVIG treatment \\
\hline Day 7 & Fever resolved & Repeat Echo normal & $\begin{array}{l}\text { Discharged on low dose aspirin - } \\
5 \mathrm{mg} / \mathrm{kg} / \text { day }\end{array}$ \\
\hline $\begin{array}{l}\text { September } \\
2012\end{array}$ & Follow up visit - no signs and symptoms & $\begin{array}{l}\text { Echo - normal } \\
\text { WBC and platelets - normal }\end{array}$ & Aspirin stopped \\
\hline
\end{tabular}

antimalarials and antibiotics. This is a common presentation also described in case reports from Ghana [3].

The first case was 3 year old child while the second was an infant. This is in keeping with epidemiologic studies from Algeria and Japan which have shown that more than $90 \%$ of children are less than 5 years of age $[2,5]$.

The children had the classical mucocutaneous features that are key to making the diagnosis. The first child had limb swelling, a skin rash and oral mucosal changes. The limb swelling was initialy thought to be sickling dactylitis which is a common condition seen in our environment and is one of the presenting signs of sickle cell disease [12].

The second child had non purulent conjuctivitis, swelling of limbs and the skin rash with involvement of the BCG scar which has been described previously [13]. Hematologic parameters are not diagnostic of kawasaki disease, however they can assist to confirm or support the diagnosis. Both our children were admitted with normal platelet counts which subsequently became elevated. This is a common finding in the second week of illness and is used as an adjunct in making diagnosis of incomplete kawasaki disease [10]. The first child had an elevated WBC count leading to a diagnosis of bacteremia and initiation of parenteral antibiotics. However, the blood culture eventually ruled out a bacteremia. The CRP was raised for both the cases as expected and eventually reduced after initiation of aspirin.

The first case was treated with both aspirin and IVIG while the second received only aspirin. The role of aspirin remains uncertain in the current era of use of IVIG, however it still remains as part of the standard

Table 2 Timeline of Case 2

\begin{tabular}{|c|c|c|c|}
\hline \multirow[t]{2}{*}{ Dates } & \multicolumn{3}{|l|}{ Relevant past medical history and interventions } \\
\hline & \multicolumn{3}{|c|}{ Previously well child with no chronic disease, growth and development appropriate for age, vaccinations complete as per schedule } \\
\hline Date & Summary from initial and follow up visits & Diagnostic testing (including dates) & Interventions \\
\hline $\begin{array}{l}\text { August } 2013- \\
\text { day } 1\end{array}$ & $\begin{array}{l}\text { Fever for } 6 \text { days and redness of eyes, lips and mouth. } \\
\text { Treated with antimalarials, antibiotics with no relief } \\
\text { On examination: dry cracked lips, conjuctival injection, } \\
\text { rash at BCG scar site and on the neck } \\
\text { Diagnosis: incomplete kawasaki }\end{array}$ & $\begin{array}{l}\text { Platelets: normal - 190,000/ } \mu \mathrm{l} \\
\text { Malaria negative } \\
\text { Echo: normal coronary arteries }\end{array}$ & High dose aspirin - 90 mg/kg/day \\
\hline Day 3 & $\begin{array}{l}\text { Fever resolved } \\
\text { Swelling of hands and feet } \\
\text { Diagnosis: complete kawasaki }\end{array}$ & 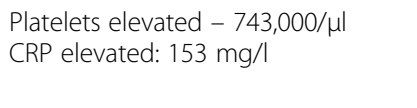 & Aspirin reduced to 5 mg/kg/day \\
\hline Day 7 & $\begin{array}{l}\text { Swelling subsided } \\
\text { Skin exfoliation }\end{array}$ & $\begin{array}{l}\text { Repeat platelet count: } 605,000 / \mu \mathrm{l} \\
\text { CRP: reduced to } 60 \mathrm{mg} / \mathrm{l}\end{array}$ & Aspirin continued \\
\hline Day 30 & Follow up visit - no signs and symptoms & $\begin{array}{l}\text { Repeat echo: normal } \\
\text { CRP }-<5 \text { mg/l } \\
\text { Platelets: normal range }\end{array}$ & Aspiring stopped \\
\hline
\end{tabular}


treatment protocols. The current treatment: IVIG is an expensive drug that is not readily available or affordable to most families in our population. A single vial of $5 \mathrm{~g}$ costs as much as 1 million tanzanian shillings which is about 450 US dollars. This hampers effective treatment which is essential to reduce the cardiovascular sequelae.

Other treatment options that could be considered are use of corticosteroids. A cochrane review of 7 trials showed benefits of reducing cardiac complications by using steroids as adjunct therapy to IVIG early in the course of illness [14]. Use of steroids alone without IVIG has not been studied. However, in low resource settings where IVIG is not available, steroids could be used to reduce the cardiovascular morbidity [15]. Other agents such as infliximab have shown promise as adjuncts to IVIG but are also not widely available in sub - saharan Africa [16].

The echocardiograms for both children were normal at baseline and on subsequent follow ups. This was reassuring since the incidence of coronary abnormalities is as high as $25-30 \%$ in patients who are not treated with IVIG [11]. Echo is a vital modality to follow up the cardiac sequelae in chidlren with kawasaki disease. However, it is not widely available in most resource limited settings and requires specialised training to operate. In Tanzania, it is only available at a few referral hospitals in the cities. This is yet another challenge in providing long-term care to children with kawasaki disease.

Kawasaki disease has not commonly been described in sub-saharan Africa. However, these 2 cases were seen over a 2 year period at a single tertiary institution. This raises concern about how many missed cases there may be which are not diagnosed or managed effectively since the fever and mucocutaneous changes eventually resolve within 3 weeks even without specific treatment. The subsequent devastating cardiovascular morbidity of this condition in children with missed diagnosis remains unknown.

The pattern of disease in the setting of tropical infections like malaria also remains unknown. Kawasaki like syndromes have been described in adults with HIV infection especially with severe immunosupression [17]. Similar illness in children infected with HIV has not been described but may also occur.

We recommend that a diagnosis of kawasaki disease be entertained for any febrile illness lasting longer than 5 days and presenting with mucocutaneous findings. Any child presenting with a prolonged fever should promptly be referred to and evaluated at a tertiary centre. Doctors and other care providers should be made familiar with this condition in order to diagnose, treat and prevent the cardiovascular morbidity and mortality.

Cases that are seen at other institutions should be published in literature so that the spectrum of the disease, its epidemiologic characteristics and its outcomes in sub-saharan Africa can be described. Equally important is that IVIG be made available at a subsidised and more affordable cost in order to benefit patients with kawasaki disease and other autoimmune conditions where it is indicated.

\section{Abbreviations}

CBC: Complete blood count; IVIG: Intravenous immunoglobulin; WBC: White blood cells

\section{Availability of data and materials}

Data sharing is not applicable to this article as no datasets were generated or analysed during the current study.

\section{Authors' contributions}

MN reviewed the case records and wrote the manuscript, NL reviewed and contributed to the final version. Both authors read and approved the final manuscript.

Ethics approval and consent to participate

Not applicable.

\section{Consent for publication}

Written informed consent for publication of their clinical details was obtained from the parent of the patient. A copy of the consent form is available for review by the Editor of this journal.

\section{Competing interests}

The authors declare that they have no competing interests.

\section{Publisher's Note}

Springer Nature remains neutral with regard to jurisdictional claims in published maps and institutional affiliations.

Received: 18 August 2017 Accepted: 8 October 2018

Published online: 23 October 2018

\section{References}

1. Burns JC, Glodé MP. Kawasaki syndrome. Lancet. 2004;364:533.

2. Nakamura $Y$, Yashiro M, Uehara R, et al. Epidemiologic features of Kawasaki disease in Japan: results of the 2007-2008 nationwide survey. J Epidemiol. 2010;20:302.

3. Badoe EV, Neequaye J, Oliver-Commey JO, et al. Kawasaki disease in Ghana: case reports from Korle Bu teaching hospital. Ghana Med J. 2011;45:38.

4. Chemli J, Kchaou H, Amri F, Belkadhi A, Essoussi AS, Gueddiche N, Harbi A. Clinical features and course of Kawasaki disease in central Tunisia: a study about 14 cases collected over a period of three years (2000-2002). Tunis Med. 2005;83(8):477-83.

5. Boudiaf $\mathrm{H}$, Achir M. The clinical profile of Kawasaki disease in Algerian children: a single institution experience. J Trop Pediatr. 2016;62(2):139-43.

6. Kim KY, Kim DS. Recent advances in Kawasaki disease. Yonsei Med J. 2016; 57(1):15-21.

7. Burgner D, Harnden A. Kawasaki disease: what is the epidemiology telling us about the etiology? Int J Infect Dis. 2005;9:185-94.

8. Lee KY, Han JW, Lee JS. Kawasaki disease may be a hyperimmune reaction of genetically susceptible children to variants of normal environmental flora. Med Hypotheses. 2007;69(3):642-51.

9. Lee KY, Rhim JW, Kang JH. Kawasaki disease: laboratory findings and an immunopathogenesis on the premise of a "protein homeostasis system". Yonsei Med J. 2012;53(2):262-75.

10. Newburger JW, Takahashi M, Gerber MA, et al. Diagnosis, treatment, and long-term management of Kawasaki disease: a statement for health professionals from the committee on rheumatic fever, endocarditis and Kawasaki disease, council on cardiovascular disease in the young, American Heart Association. Circulation. 2004;110(17):2747-71.

11. Terai M, Shulman ST. Prevalence of coronary artery abnormalities in Kawasaki disease is highly dependent on gamma globulin dose but independent of salicylate dose. J Pediatr. 1997;131(6):888.

12. Bainbridge $R$, Higgs $D R$, Maude $G H$, Serjeant $G R$. Clinical presentation of homozygous sickle cell disease. J Pediatr. 1985;106(6):881. 
13. Uehara R, Igarashi H, Yashiro M, Nakamura Y, Yanagawa H. Kawasaki disease patients with redness or crust formation at the Bacille Calmette-Guérin inoculation site. Pediatr Infect Dis J. 2010;29(5):430.

14. Wardle AJ, Connolly GM, Seager MJ, Tulloh RM. Corticosteroids for the treatment of Kawasaki disease in children. Cochrane Database Syst Rev. 2017;1:CD011188.

15. Singh S, Newburger JW, Kuijpers T, Burgner D. Management of Kawasaki disease in resource-limited settings. Pediatr Infect Dis J. 2015;34(1):94-6.

16. Jone PN, Anderson MS, Mulvahill MJ, Heizer H, Glodé MP, Dominguez SR. Infliximab plus intravenous immunoglobulin (IVIG) versus IVIG alone as initial therapy in children with Kawasaki disease presenting with coronary artery lesions: is dual therapy more effective? Pediatr Infect Dis J. 2018; 37(10):976-80.

17. Stankovic K, Miailhes P, Bessis D, Ferry T, Broussolle C, Seve P. Kawasaki-like syndromes in HIV-infected adults. J Inf Secur. 2007;55:488-94.

Ready to submit your research? Choose BMC and benefit from:

- fast, convenient online submission

- thorough peer review by experienced researchers in your field

- rapid publication on acceptance

- support for research data, including large and complex data types

- gold Open Access which fosters wider collaboration and increased citations

- maximum visibility for your research: over $100 \mathrm{M}$ website views per year

At $\mathrm{BMC}$, research is always in progress.

Learn more biomedcentral.com/submissions 